
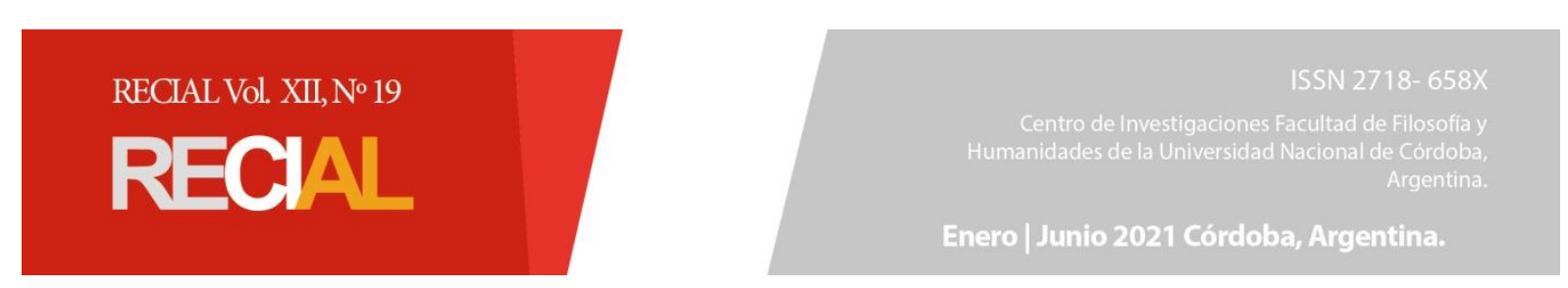

\title{
El alejandrinismo en la poesía de Luis Alberto de Cuenca
}

Facundo Giménez ${ }^{*}$

\section{Resumen}

La poesía de Luis Alberto de Cuenca (Madrid, 1950) se caracteriza por su gran capacidad de vincular diversas tradiciones, objetos textuales y épocas. Este rasgo ha distinguido a su poesía desde sus inicios en la década del setenta y se ha mantenido constante en su poesía de madurez. Este trabajo se propone indagar en torno de esta apertura del texto poético, para proponer un posible modelo al cual puede remitirse esta comprensión de la cultura: el alejandrinismo. Para ello, recuperaremos algunas nociones básicas del periodo helenístico para, posteriormente, observar cómo es la recuperación del modelo alejandrino en unas composiciones poéticas que llevan el título de variaciones. El análisis de la apropiación de este modelo permitirá explicar, además de la citación de referentes propios del periodo histórico, una inclinación temática y compositiva hacia lo menor.

Palabras claves: poesía española, alejandrinismo, variaciones, Luis Alberto de Cuenca

\section{Alexandrianism in Luis Alberto de Cuenca's poetry}

\begin{abstract}
The poetry written by Luis Alberto de Cuenca (Madrid, 1950) is characterized by its great ability to link different traditions, texts and ages. This feature has distinguished his work since the early seventies and it has remained part of his last texts. The purpose of this current paper is to analyse the versatility of his poems, to suggest a possible model to wich this understanding of culture can be referred to: the alexandrianism. To do so, we will make reference to some basic terms from helenistic period. Later, we will observe the recovery of the alexandrian model by some pieces of poetry entitled "variations". Finally, we will explain some thematic tendency to the "minorness", that also could be explained by the alexandrian model.
\end{abstract}

Keywords: spanish poetry, alexandrianism, variations, Luis Alberto de Cuenca

\footnotetext{
* Doctor en Letras, Universidad Nacional de Mar del Plata. Pertenece al Centro de Letras Hispanoamericanas, Mar del Plata, Argentina. facugimenez@gmail.com.

Recibido 05/03/2021. Aceptado 23/05/2021.
} 


\section{Sade y Barbarella, Homero y George Lukas, Séneca y Humphrey Bogart o Federico García Lorca y la Movida}

Probablemente uno de los rasgos más singulares de la poesía de Luis Alberto de Cuenca (Madrid, 1950) sea su capacidad de conciliar tradiciones, en apariencia, lejanas. Iniciada en los setenta en pleno apogeo de los novísimos y, durante las décadas siguientes, asociada al giro comunicativo de las poéticas de la experiencia, su obra ha sido caracterizada, en reiteradas ocasiones, de posmoderna. El uso de esta etiqueta puede entenderse como una conexión entre la mencionada capacidad conciliadora del texto poético y una coyuntura filosófica, política e histórica, que, en la España del tardofranquismo y el periodo transicional, se vuelve evidente. Su producción poética, en este sentido, durante su aventura novísima, se inscribe en aquella vertiente pop y contracultural que José María Castellet (1970) denominaría como "coqueluche" y, bajo un régimen escritural hermético, inicia un diálogo con textualidades novedosas como la historieta, la canción y el cine. Con el proceso transicional y la vuelta a la democracia, este diálogo no solo no cesará, sino que, además, será reconducido hacia formas más tradicionales, menos problemáticas $\mathrm{y}$, por usar un adjetivo caro al autor, más claras. Más allá de esta consideración, que por otra parte ya ha sido desarrollada por Javier Letrán en La poesía postmoderna de Luis Alberto de Cuenca (2005), es importante observar - y resaltar - cómo su producción incluye una variedad de objetos culturales provenientes de diversos campos, disciplinas y épocas que, una vez capturados por la maquinaria poética luisalbertina, conversan entre sí, se interpelan y acaban por reescribirse. $\mathrm{Su}$ escritura se encuentra poblada de anacronismos intempestivos, encuentros impensados y dispersiones irradiantes. De esta forma, la historieta y el cine dialogan con la épica antigua, la lírica provenzal o el Barroco, y, en relativa armonía, conviven Sade y Barbarella, Homero y George Lukas, Séneca y Humphrey Bogart o Federico García Lorca y la Movida, por poner solamente algunos ejemplos. No parecen existir elementos que se resistan a adherirse en la erudición multiforme de sus poemas. Una vez recuperados por su voz, se inicia lo que, en un poema de la década del ochenta, Luis Alberto de Cuenca supo describir como una "fiesta":

Todo está preparado: las antorchas humanas, el caviar, el salmón, la coca, los faquires, la naumaquia, el desfile de misses alienígenas, los viajes a la luna con Cyrano y Münchhausen, la pelea entre fieros hologramas desnudos, la jaula con Spiderman y Hulka entrelazados, todas las atracciones que apetece ver juntas. (de Cuenca, 1987, p. 59).

La principal consecuencia de esta forma de apertura de sus textos, comprensiblemente, es la reelaboración de las nociones de cultura y tradición, que son entendidas menos como una serie de compartimientos estancos destinados a cada disciplina artística que como un conjunto amplio que admite - y requiere - ciertas transacciones para su desarrollo. Así, las fronteras entre las tradiciones de la imagen y las tradiciones literarias, por ejemplo, tienden a volverse borrosas, y el cruce constante de territorios, de un campo a otro, se convierte en una convivencia conciliada y enriquecedora entre diversos lenguajes. A su vez, la poesía luisalbertiana desarticula las restricciones que separan géneros, dicciones y jerarquías que habían confinado al discurso poético a su propia especificidad. Es, por lo tanto, una escritura que busca romper el cerco trazado, en particular, por la estética novísima, para resguardar a 
una poesía exclusivamente para poetas. Así lo declara de Cuenca (1999) a finales de la década del noventa:

Me gusta recordar que mi poesía suele gustarle a gente que no lee poesía o piensa que la poesía es un asunto de señoras cursis y/o de tarados. Eso demuestra que la poesía puede y debe salir del ghetto, de las mafias, del malditismo. De su propia y tediosa iconografía. (P. 2).

Este funcionamiento de la cultura, caracterizado por la permeabilidad, por el intercambio, por el constante juego asociativo y por la lógica de la permuta y la apropiación habilita, a su vez, un pacto escritural cimentado en la intertextualidad y la reescritura. Ubicada en las antípodas de la pretensión de originalidad romántica, la poesía de Luis Alberto de Cuenca apuesta, en su proceso creativo, por la construcción de un discurso literario cuya operación privilegiada sea la de vincularse con el amplio - y ampliado, podríamos agregar - conjunto de la tradición. Su poesía, en efecto, presenta una serie de homenajes y alusiones que vinculan el proceso creativo del poeta con la reelaboración del corpus canónico.

Esta insistente aproximación del texto poético a la tradición que propone la escritura luisalbertiana la vincula con otros modelos retóricos del pasado. La recuperación de la imitatio, por un lado, remite a modalidades de representación clásica que, en su forma de captar y exponer el artificio, pueden ser asociadas a la estética de la Ilustración. Por otro lado, ese juego ingenioso que despliega y asocia diversos enunciados puede vincularse con la postulación del régimen estético del Barroco que realiza Baltasar Gracián en el célebre tratado Agudeza y arte de ingenio (1648). Sin embargo, más allá de estas filiaciones, probablemente, el enlace con la tradición que propone su poesía nos remita a un modelo evidentemente más antiguo que nuestro poeta conoce en detalle: el alejandrinismo.

Esta concepción de la cultura proveniente del mundo clásico puede rastrearse no solamente en una serie de temas, personajes, tropos o escenas, sino, además, en la particular concepción que presenta Luis Alberto de Cuenca de la tradición y la cultura. De esta forma, la veta alejandrina parece proveer un hilo conductor a partir del cual puede explicarse esta singular apertura del texto poético a la cual nos referíamos anteriormente. A continuación, explicaremos la conexión entre el alejandrinismo y la poesía luisalbertiana, para luego abordar un género que lo vincula con dicha tradición.

\section{El alejandrinismo: una conexión lejana pero obvia}

El alejandrinismo es un régimen cultural de la Antigüedad, que se desenvolvió en la costa del Mediterráneo después de la conquista de Alejandro Magno, y que duró aproximadamente unos tres siglos, desde fines del siglo IV a fines del siglo I antes de Cristo, hasta ser absorbido por la civilización romana. Históricamente la importancia de este periodo - también llamado helenismo - reside en la ruptura de las estrechas fronteras de la polis y en la apertura de un camino libre a la helenidad para su difusión colonizadora y cultural por toda la ecúmene (Lesky, 2003, p. 725). Este proceso culturalmente implicó, por un lado, la expansión de la cultura griega y su consecuente canonización, pero, por otro lado, un reajuste de las tradiciones regionales que se verá explicitado en una exacerbada conciencia del propio legado cultural. Alejandría será el epicentro de este fenómeno, que favorecerá, a partir de la fundación de instituciones como el museo o la biblioteca, el intercambio de ideas entre destacados filósofos, poetas y científicos (Brioso Sánchez, 1988; Lesky, 2003; Perrotta, 1925). Esta urbe, al igual que otras fundadas durante ese periodo, contará con una 
infraestructura de proporciones descomunales que fomentará modalidades de vida manifiestamente urbanas ${ }^{1}$, así como también la consolidación del cosmopolitismo y el individualismo como rasgos distintivos.

En este marco, los géneros poéticos de difusión más popular, como la épica, la oda coral, la comedia y la tragedia, comienzan a ser desplazados por un arte más restrictivo, acorde con la reconfiguración del espacio público que, por entonces, abandona la democracia y se cierne en torno de diversas monarquías autárquicas (Bowra, 1958, p. 176). La erudición y la lupa filológica inspiran una nueva forma de componer que aspirará a un lector minoritario. Escribe Calímaco de Cirene (1974) en su "Autorretrato": "Odio el poema cíclico, aborrezco el camino / que arrastra aquí y allá a la muchedumbre; / abomino del joven que se entrega sin discriminación, / y de la fuente pública / no bebo: me repugna todo lo popular"(Calímaco, 1974, p. 71). Esta literatura, por lo tanto, no está dirigida a las multitudes; por el contrario, su riqueza en presupuestos solo es accesible al entendido y su lenguaje rehúye de adoptar, por lo menos de forma inalterada, las fórmulas de la tradición, y, además, se distancia de la expresión coloquial (Lesky, 2003, p. 731). Son mal vistos el gran pathos así como también la emotividad franca, y la búsqueda de dominio en la expresión favorece un conocimiento, en términos retóricos, del poema. Los poetas alejandrinos - entre los que podríamos destacar, además del mencionado Calímaco, a Licofrón, a Bión, a Teócrito o Euforión de Calcis- se caracterizan por una sólida formación filológica y cultural que aparece desplegada en sus composiciones. Encarnan, en este sentido, la figura de poetas-filólogos o doctus poeta como probablemente en ningún otro periodo previo de la historia (Suárez Martínez, 2010, p. 30). Su predilección por la farsa, por los detalles ínfimos, por las escenas de la vida cotidiana, por otra parte, ha sido observada por la crítica como una inclinación hacia el realismo que, sin embargo, debe ser comprendido como una vertiente estrictamente literaria. Este universo textual y su forma declaradamente menor de articular la tradición pueden explicarse a partir del posicionamiento de estos escritores en torno a un legado cultural ya consolidado. El alejandrinismo, en efecto, es una cultura construida al margen de una herencia inconmensurable, la de Homero, Píndaro, Hesíodo, Eurípides, Sófocles y Safo. Al poeta alejandrino, atravesado por una helenización y, por lo tanto, formado en sus bordes, solo le queda entregarse a una labor libresca, tan erudita como minúscula, que, sin embargo, dará cuenta de una reconfiguración del enlace de la literatura con lo que podríamos llamar su territorialidad $^{2}$. El rechazo de los grandes ciclos y la consecuente construcción de una literatura menor responde, por consiguiente, a una reformulación de un régimen estético que apostará por la construcción de un espacio imaginario, el de la literatura, que dé cuenta del carácter expropiatorio, es decir, impropio, de la labor del poeta con respecto a un corpus tradicional tan monumental y naturalizado como ajeno y extraño. Ello ha contribuido atizado, además, por el refinamiento de sus composiciones y el declarado abandono de los grandes públicos - a la creación de una imagen intelectual, en cierta forma, aristocrática, epigonal, gratuita y vacía de sus obras, como la que acusa Cantarella al calificar de "frías e intelectuales" (de Cuenca, 1974, p. 243) a las composiciones de Calímaco, o la que podemos leer en un texto de Maurice Bowra (1958) como el siguiente:

Privada de sus tradiciones, transportada a climas exóticos, amparada y sometida a la vez por el despotismo, la literatura nunca volvió a visitar las cumbres de antaño. Pero, aun dentro de esta esfera limitada, todavía el genio griego encontró algunas cosas nuevas que expresar y nuevas maneras de expresarlas. (P. 176). 
La opinión que vierte este historiador de la literatura parece evaluar particularmente cierta zona barroca, manierista y, por momentos, hermética y oscura, como la que podemos encontrar en Licofrón o Euforión de Calcis. Por otra parte, esta observación parece remitir a un lugar común en los estudios de literatura griega que enfrenta la escritura declaradamente menor de los alejandrinos a la grandeza de la épica o de la tragedia. Ello, sin embargo, no puede negar la calidad y la pervivencia de los textos alejandrinos que lejos se encuentra de haber mermado luego del periodo; menos aún se puede objetar la comprensión de la labor poética que ha sido valorada, incluso, por poetas actuales como Ezra Pound, Jorge Luis Borges o por el propio Luis Alberto de Cuenca ${ }^{3}$. Gennaro Perrotta realiza una observación que, quizá, colabore a pensar por fuera de esta imagen cristalizada el magisterio de los alejandrinos:

Hoy, cuando se habla de Alejandrinismo, se piensa enseguida en una elegancia formal, exquisita, sin vigor y sin contenido sincero, en un arte que gusta de juegos y refinamientos exteriores, sin vida y sin alma. Pero es un error reducir el Alejandrinismo a algunos de sus caracteres externos y deficientes. Una civilización nueva, tan rica de vida, tan llena de empuje, todavía la consideran muchos como una civilización de epígonos fatigados, de imitadores sin genio, como una civilización de decadencia. (Perrotta, 1925).

Volviendo a nuestro poeta, resulta evidente que la tradición clásica ocupa un lugar privilegiado en su escritura, en especial, si revisamos la insistente recuperación de temas, tópicos, tropos y personajes provenientes de esa cultura. La evidente inclinación por el mundo clásico, no obstante, no solamente define un elenco de elementos recurrentes, sino que, además, influye en su forma de comprensión del espacio de lo literario. En efecto, esa forma de operar con la tradición y la cultura que explicábamos en la primera parte de este trabajo es, según observa el filólogo Carlos García Gual (2013), de raigambre manifiestamente helenística:

La poética helenística, modernísima en muchos aspectos —en la línea clara que va desde Calímaco a Ezra Pound-, manejaba los mitos con maestría en ese peculiar "arte alusiva" que sabe combinar el aprecio por el mundo prestigioso y mágico con la ironía literaria. Los viejos mitos (con sus dioses y héroes famosos) eran ya para los poetas helenísticos, tan eruditos y descreídos, un sutil juego literario. Pero no por ello falto de emotividad. Y parecido es el empeño mitológico que encontramos en muchos de los poemas de Luis Alberto, con una ironía que ha ido acentuándose, a mi parecer, con los años y los libros. (P. 164).

En este punto, es importante explicar que Luis Alberto de Cuenca es un gran conocedor de la tradición cultural helenística. Quizá, el punto de contacto más evidente sea su formación filológica clásica y, en particular, la escritura de dos textos académicos en los que aborda la poesía alejandrina. Ambos textos, su tesina de licenciatura y su tesis doctoral, dedicadas a Calímaco de Cirene y a Euforión de Calcis, respectivamente, fueron publicados de forma fragmentaria en revistas académicas y, luego, reunidos en dos libros editados durante la década del setenta (Brioso, 1987; de Cuenca, 1974, 1976, 2006). A su vez, el contacto con la 
poesía alejandrina le llega de forma indirecta por el magisterio de Ezra Pound, T. S. Eliot o el mismísimo Constantino Kavafis, todos ellos poetas que recuperan la tradición helenística y que nuestro autor sigue muy de cerca desde temprana edad. Por lo tanto, la postulación de ciertas modalidades del alejandrinismo en su obra responde, en alguna medida, a una conexión cultural que el poeta conoce en profundidad y que, ciertamente, alienta en su poesía, en particular, si observamos la veta epigramática o la insistente labor filológica de la que dan cuenta sus poemas.

\section{¿Un alejandrinismo de "línea clara"?}

En los estudios académicos dedicados a la obra de Luis Alberto de Cuenca suelen demarcarse dos zonas claramente diferenciables. La primera se encuentra vinculada con una poesía de juventud, en la cual - con mayor o menor acuerdo entre los críticos- son reconocidos Los retratos (1971), Elsinore (1972) y Scholia (1978). Esta primera franja de su producción se encuentra vinculada, tanto en su contexto como en sus aspiraciones, con la estética novísima que José María Castellet supo describir en un libro tan oportuno como polémico como fue Nueve novísimos poetas españoles (1970). Durante la década del setenta, la figura autoral de Luis Alberto de Cuenca es la de un poeta oscuro y doctísimo, y sus poemas aspiran a una oscuridad expresiva de difícil captura. La publicación de La caja de plata (1985) marca el inicio de la segunda zona de su producción que será bautizada por el propio poeta, utilizando una etiqueta proveniente del cómic, como de "línea clara". Si la poesía novísima de Luis Alberto de Cuenca puede ser entendida como una poesía de juventud, el periodo de "la línea clara" es un momento de madurez de su obra poética. Su poesía, a partir de la década del ochenta, abandona definitivamente el magisterio de oscuridad $\mathrm{y}$, muy por el contrario, comienza a valorar otros atributos del texto, como lo son la asequibilidad lectora o la claridad expresiva. Este cambio tan rotundo y único en la poesía española contemporánea, como resulta comprensible, acaba por instaurar una doble inscripción de su obra: una que la vincula a la poesía novísima y otra que la vincula a la poesía producida en la década del ochenta. Este doblez jánico de su obra, que se disputa entre un pasado oscuro y un presente claro, y entre la gestualidad ampulosa de los novísimos y la contención dialogadora de la generación poética de los ochenta, parece haber también afectado la comprensión del rescate del alejandrinismo que hace de Cuenca en su obra.

Respecto de esta afirmación, es preciso reconocer que, hasta el momento, existe cierto acuerdo en la crítica con respecto a la presencia del alejandrinismo en su obra. Sin embargo, su inscripción en el alejandrinismo ha sido comprendida como un rasgo privativo de la primera etapa poética (1971-1978), vinculada estéticamente con el fenómeno de los "novísimos". El primer crítico en percatarse de esto fue Ángel Sierra de Cózar (1991): 
La poesía de su primera década es culturalista, alejandrina, nace de los libros y de los museos, de las literaturas del mundo. Prefiere las leyendas, los mitos, los escenarios exóticos, las figuras marginales u olvidadas. Arraiga el presente por la misma vía y reivindica los géneros menores, la novela negra y su cine, la de terror, el comic. El índice es babélico, los títulos proclaman cosmopolitismo y osadía... el poema puede consistir en la fusión breve de objetos, situaciones, nombres propios, sin fronteras de tiempo ni de espacio, o en la secuencia larga de imágenes autónomas, inconexas en apariencia, a las que puede aunar un personaje el cuadro irreal de varias épocas... La técnica oscila entre la yuxtaposición elíptica, y la enumeración onírica... Su objeto es impregnar de un clima, crear una atmósfera, un estado inconexo. Pero cuando es clara, es distante, tibia como un madrigal. Otras veces a fuerza de distinguirse, de individualizar las claves de sus mundos, el poeta se vuelve hermético, y el poema, mudo. (P. 84).

Lo que parece indicar Sierra de Cózar como un rasgo del alejandrinismo es la profusión cultural de su poesía, su construcción libresca o museística, en otras palabras, su culturalismo. A su vez, la construcción poemática que describe corresponde a cierta zona del alejandrinismo, oscura, hermética y barroca, como la de Licofrón, Bión o, el tan apreciado por nuestro autor durante la década del setenta, Euforión de Calcis. El alejandrinismo es, en conclusión, considerado una etapa o periodo en la carrera de nuestro poeta que será, durante la década del ochenta, superada. A la misma conclusión parece llegar Luis Suárez Martínez en su completo y meticuloso libro dedicado íntegramente a la recuperación del mundo clásico en la obra luisalbertiana. En dicho volumen, el crítico español entabla una relación entre "poética alejandrina y poética novísima" y aborda la obra de nuestro autor a partir del paso del alejandrinismo - como sinónimo de manierismo - a otra poética de "línea clara" o clasicista. El autor de La tradición clásica en la poesía de Luis Alberto de Cuenca (2010) entiende este tránsito, iniciado en Scholia, a partir de la disolución de los rasgos manieristas más estridentes de la etapa novísima. La propuesta de este crítico, sin embargo, no indica el abandono de todos los rasgos y prácticas que podríamos llamar alejandrinas, sino, más bien, una continuidad entre alejandrinismo y clasicismo:

Así pues, esos dos modos poéticos constituyen, en realidad, variantes diferentes de una raíz estética común que es la alejandrina o manierista (en el sentido general que Curtius aplica a este término). En consecuencia, la evolución de la lírica luisalbertiana no ha de interpretarse como el paso de una poética manierista a una poesía clasicista de signo opuesto, sino como el paso de un manierismo de la forma a un manierismo del contenido... En este sentido, el clasicismo formal (regularidad métrica) y la sencillez expresiva signo aparente de naturalidad clásica- de su poética actual ocultan un minucioso artificio, una rigurosa tensión linguiística y, en definitiva, un velado culto por la forma y por el ingenio. De ahí su preferencia por el epigrama, el género lírico más adecuado para sus juegos poéticos (que buscan también divertir al lector), con su gusto por la paradoja, la antítesis, la hipérbole... Tanto estos aspectos estilísticos como su actitud frecuentemente paródica ante la tradición literaria apuntan claramente, a nuestro juicio, a una estética más manierista que clásica. (Suárez Martínez, 2010, p. 328). 
Solamente basta con recomponer el intrincado sistema referencial de su poesía más reciente para comprender que la salida del culturalismo, que había sido anunciada por García Posada como un rasgo generacional, no es tal en la obra luisalbertiana. Por el contrario, sus libros tienden, aunque mediante otros procedimientos, a poner sobre la superficie su eminente construcción culturalista. La recuperación del alejandrinismo, tal como podemos inferir del siguiente fragmento de su tesina de licenciatura, será entendida como una apelación hacia un corpus tradicional que prescinde de un supuesto origen biográfico:

En este ambiente, pues, de culto a los valores intelectuales va a desarrollarse la personalidad humana y artística de Calímaco. Por ello, es lógico que el poeta, al redactar sus epigramas (composiciones circunstanciales, obras menores en fin), no dé más valor personal a la anécdota que el que se desprenda de su funcionalidad literaria. Pero no por ello los epigramas calimaqueos van a ser "freddi e letterari". Cantarella, como tantos otros estudiosos afanados tan sólo en ordenar, clasificar y juzgar según moldes fijados de antemano, parece identificar, con evidente falsedad, lo que a él le parece «frío y literario» (por su educación estética, discutible en todo caso) con lo que de verdad es «frío y literario» en literatura. He dicho bien: en literatura. Porque, ¿qué otra cosa son los epigramas de Calímaco sino «literatura», qué otra cosa es la Commedia o La vida es sueño sino «literatura», qué otra cosa es la literatura sino «literatura»? La vida es otra cosa: quédese para los aficionados a la psicología o al -también literario- género biográfico. (de Cuenca, 1974, p. 243).

Este posicionamiento de Luis Alberto de Cuenca es leído por Suárez Martínez como el sustento de una literatura, como la de la etapa novísima, desinteresada por cualquier coordenada contextual y de carácter evidentemente barroco. Ello, como queda demostrado en su estudio, parece ser cierto. Sin embargo, esta declaración puede ser leída también como la habilitación de un espacio escriturario en el que la adopción de lo literario - ese rechazo de lo biográfico o psicológico como sustento del texto- provoque el reconocimiento del carácter ficcional de la escritura y, por consiguiente, de las relaciones que establece con la tradición. Despejar, como lo hace programáticamente la poesía novísima, la conexión pretendidamente necesaria del poema con una praxis ética o política, no obstante, no implica abandonarse a un juego vacío, gratuito y sin importancia ${ }^{4}$. Se trata, antes bien, de sostener una condición autónoma del texto literario que deberá regirse a partir de mecanismos, reglas y trayectorias que le son propias ${ }^{5}$. De este modo, tanto en su etapa novísima como aquella que él mismo llamó de "línea clara", Luis Alberto de Cuenca va a reclamar del poema, por un lado, un rigor técnico, que podría traducirse como una economía interior del texto, impulsada por un repertorio de procedimientos y combinaciones, y, por otro, una exigencia como la de "necesidad" del poema, dirigida a un posicionamiento que le es externo, que lo comunica con su historia y que designa el lugar relevante que ocupa. En todo caso, habría que decir que la adopción del alejandrinismo durante el periodo de "línea clara" instaurará una modalidad de escritura que se encuentra vinculada estrechamente con una forma de relacionarse con la tradición. Ello puede verse en la importancia que, en general, adopta la reescritura en sus libros y, en particular, en una serie de textos que identifica como "variaciones" que recuperarán la veta epigramática alejandrina ${ }^{6}$. 


\section{Variaciones: la apertura como combinatoria}

La variación es una técnica compositiva del lenguaje musical que recupera un material previo y lo vuelve a presentar con algún cambio, ya sea en la melodía, el ritmo, la armonía, el contrapunto, el timbre o la orquestación. Se trata de una forma musical, cultivada con diverso éxito, que se sustenta en un trabajo combinatorio sobre un corpus musical conocido ${ }^{7}$. En la poesía, la transposición de esta técnica implica una de las tantas formas de reescritura alejandrina que recobra un hipotexto - reconocible e imprescindible para el texto posteriory lo presenta con algún cambio - que va desde la mera citación o traducción hasta una modificación más ostensible-, estableciendo, de esa forma, una relación constitutiva con la tradición ${ }^{8}$. En un muy reciente artículo, Juan José Lanz se refiere al uso de esta técnica en una serie de textos pertenecientes a El hacha y la rosa, en los que de Cuenca, lejos de intervenir los textos de origen, prefiere traducirlos: "Allí encontramos traducciones directas", nos explicará Lanz, "en las que no se ha realizado prácticamente ninguna variación sustancial a partir del texto original, apropiadas por el yo textual que configura el poemario" (Lanz, 2018, pp. 77-78). En el libro Bloc de otoño, sin embargo, el uso de este género resulta, si no más ambicioso, al menos sí claramente diverso, en la medida en que se refuerza el carácter combinatorio de la variación. A continuación, nos centraremos en dos casos que dan cuenta del carácter alejandrino de este tipo de composición.

Nos referimos a los textos titulados respectivamente "Variación sobre un tema de Catulo" y "Variación sobre otro tema de Catulo". En principio, podríamos observar que, desde la titulación, de Cuenca nos declara el carácter ostensiblemente no original de su texto, que se ubica en el margen de una tradición canónica para, aunque con sus cambios, recrearla. Esta forma de operar con la tradición es la misma utilizada por los poetas alejandrinos. Tal como sostiene Giusseppe Giangrande, ellos consideraban que la "originalidad del texto" residía en insertar y mezclar "palabras modernas, o sentidos modernos de palabras de origen antiguo, en un contexto que consta de términos tradicionales, de antigua ascendencia poética" (Giangrande, 1984, p. 163). Esta técnica provocaba, a veces, un arte recusatorio que, simultáneamente, se oponía y dependía de los grandes poetas griegos, y, casi siempre, un arte combinatorio que depositaba el valor de la escritura en el uso diferencial de la tradición. Volviendo a las variaciones luisalbertianas, la recuperación, además, de un poeta latino como Catulo, poeta novus latino en la senda neotérica iniciada por los alejandrinos, instala un linaje en el que de Cuenca parece querer inscribirse. La lógica de la variación, a su vez, requiere, por parte del lector, de un reconocimiento del hipotexto, favoreciendo una mecánica que funciona prioritariamente, podríamos decir, dentro de la literatura. Yendo a los textos específicamente, el primero recupera el "Carmen V" en el que Catulo invita a "vivir" a Lesbia la pasión de su amor a pesar de la mirada ajena ("iVivamos, Lesbia mía, y amemos, y todos los rumores de los viejos, demasiado severos, valorémoslos en un solo céntimo!." [Catulo 1993, p. 67, vv. 1-5]), pero invirtiendo esa invitación por otra de carácter opuesto:

Muramos juntos, Lesbia mía, amémonos

como fieras en celo hasta el final,

sin dar tregua al deseo. Consumamos

nuestros cuerpos ajados en la hoguera

de nuestras obsesiones favoritas,

como herejes relapsos que persisten

en su error de quererse para siempre. (de Cuenca, 2018, p. 84). 
$\mathrm{Al}$ repetir la estructura del primer verso, la versión luisalbertiana refuerza la cercanía con el hipotexto; la voz poética, de esa forma, interpreta el poema de Catulo solamente ofreciendo una modificación. Sin embargo, ese cambio, la inversión del verbo "vivir" por "morir", se constituye como una transgresión del poema previo que se ve obligado, en un segundo movimiento de la variación, a alejarse del carpe diem y a acercarse a una visión vinculada más con el imaginario amoroso romántico. Este rescate del romanticismo, atravesado por el filtro del decadentismo, del mal du siècle y la melancolía, le permitirá construir la imagen del suicidio amoroso, entre cuyos antecedentes destaca los casos de Heinrich von Kleist y de Aldolphine "Henriette" Vogel (1911), de Lotte Altman y Stefan Zweig (1942), y la figura decimonónica del flâneur:

\author{
Y, después, suicidémonos, siguiendo \\ el ejemplo de Heinrich y de Henriette, \\ o el de Lotte y Stefan para que \\ nadie pueda decir que nuestro amor, \\ como el de tanta gente, fue fugaz, \\ y para que el flâneur de cementerios \\ pueda leer, inscrito en nuestra tumba, \\ el siguiente mensaje: «Ahí os quedáis. \\ Nuestra es la eternidad». (de Cuenca, 2018, p. 84).
}

De la misma forma, el segundo texto al que hacíamos referencia recupera una pregunta de Lesbia al poeta en el "Carmen 7" ("Me preguntas cuántos besos tuyos, Lesbia, bastarían para saciarme.") y ofrece una variación que la devuelve a otro ámbito y a otra tradición que parecen resultar incompatibles con el hipotexto clásico. Nos referimos al cambio de interlocutor que, a diferencia de la variación anterior, dejará de ser Lesbia y será el personaje vampírico y seductor de la novela de Sheridan Le Fanu que lleva su nombre, Carmilla (1872). La inclusión de este personaje ofrecerá, evidentemente, otra economía del afecto, vinculada más a la sensualidad del género gótico que al discurso amoroso catuliano: 
Me preguntas, Carmilla, cuántos besos

tuyos me saciarían esta noche

de la razón en que las criaturas

lovecraftianas han tomado el mando

y no se mueve nadie sin permiso.

$\mathrm{Y}$ te respondo que con uno solo

con dientes (no con lengua) que horadase

mi yugular tendría suficiente.

No quiero seguir vivo en este mundo,

donde no hay más que idiotas y tarados

que han prohibido los mitos y los héroes. (de Cuenca, 2018, p. 85).

La respuesta, que en el poema de Catulo es ciertamente hiperbólica, le permitía explayarse en un ejercicio erudito y funcionaba a la manera de una excusa que el lector reconocía y sobre la cual la escritura desplegaba una imaginación que recuperaba ciertos lugares de la tradición, ofreciéndonos veladamente un homenaje a Calímaco de Cirene (Ponce Hernández, 2013):

Pues bien: cuantos granos de arena libia hay en Cirene, fértil en laserpicio, entre el oráculo del ardiente Júpiter y el venerable sepulcro del viejo Bato, o cuantos astros, cuando calla la noche, vigilan los furtivos amores de los seres humanos, tantos son los besos, dados por ti, que le bastan para saciarse al loco de Catulo, de forma que ni los curiosos podrían contarlos, ni hechizarlos una lengua maligna. (Catulo, 1993, p. 70).

La construcción del texto que va desde el grano de arena hacia las estrellas del firmamento en su intento de cifrar lo innumerable da cuenta, al mismo tiempo, de un rigor técnico que, bajo la figura de la labor limae, intentaba inscribirse en la trayectoria de la poesía alejandrina (Alonso Gamo, 2004, p. 67). En el poema de de Cuenca, esa respuesta será más bien escueta, pero también servirá de excusa para el despliegue, aunque de signo diverso, de una erudición igualmente compacta. La escena amorosa que recrea el poema luisalbertiano se insertará, como pudimos ver, en una trama gótica y recuperará un universo narrativo que poco tiene que ver con el mundo clásico. Ello, a su vez, va a producir una filiación doble que, por un lado, irrefutablemente remitirá al hipotexto latino, pero que, por otro, lo trastocará y lo forzará a una conexión, hasta entonces, inédita e insólita. Este doble direccionamiento que ofrece el texto luisalbertiano tiene, como podemos observar en el cierre, la finalidad de abrazar el carácter ostensiblemente ficcional de la escritura ${ }^{9}$.

\section{Conclusión}

El alejandrinismo luisalbertiano, por lo tanto, consiste no solamente en la reescritura como motor de su producción, sino en la interacción de diversas tradiciones. El cotejo, la ventriloquía y la asociación insólita serán los mecanismos de una actividad irónica, tal como observaba Carlos García Gual en el fragmento citado, que ve progresar un texto con la capacidad de articular lo aparentemente diverso, inconexo e irreconciliable. La poesía luisalbertiana, de esta forma, se dota de una amplitud y permeabilidad que comprende a la cultura y a la tradición como un diálogo siempre recomenzado y, por ello mismo, novedoso. 
Esta modalidad del alejandrinismo observada en este breve acercamiento, a su vez, puede apoyarse en una serie de rasgos que la poesía del madrileño presenta, como la apertura del horizonte referencial, la hibridez genérica, la preocupación por la tekné compositiva, la inclinación por los textos breves, el juego de alusiones, la exploración psicológica de los personajes, etcétera, que evidentemente remitirán a una praxis escrituraria proveniente del magisterio de dicha escuela helénica (Arrondo, 2016; Bowra, 1958; Brioso Sánchez, 1988; Lesky, 2003).

Para finalizar es importante destacar que, como se desprende de los ejemplos analizados, resulta también de raigambre evidentemente alejandrina la inclinación temática y compositiva hacia lo menor que tienen sus poemas. En este sentido, los poetas alejandrinos, por lo general, evitaban producir una literatura extensa, elevada y solemne, como la de los grandes ciclos épicos. Calímaco, en Respuesta a los Telquines, por ejemplo, habla de una "musa sutil" y de un canto que evite los grandes caminos y se desplace por estrechos senderos (Brioso, 1987, p. 123). Lo menor en la poesía de Luis Alberto de Cuenca implica un acercamiento a la cotidianidad, a las figuras del discurso amoroso y a "los temas de siempre"10. Se trata de un movimiento que le da la espalda - de la misma forma que lo hacían los alejandrinos - a los grandes relatos colectivos (el compromiso, la historia, la política, etc.) en aras de una privatización del fenómeno poético.

\section{Referencias}

Alonso Gamo, J. M. (2004). Estudio Preliminar. En Cayo Valerio Catulo, Poesías completas: Traducción y estudio preliminar (pp. 15-85). Guadalajara: AACHE.

Arjona, D. (13 de junio de 2011). Luis Alberto de Cuenca: "Desde pequeñito he sido un friki y lo seguiré siendo". El cultural. Recuperado de https://elcultural.com/Luis-Alberto-de-

Cuenca-Desde-pequenito-he-sido-un-friki-y-lo-seguire-

siendo\#: :text=He\%20sido\%20un\%20friki\%20desde,friki $\% 20$ que $\% 20 \mathrm{al} \% 20$ especialista $\% 20$ fr\% $3 \%$ ADo

Arrondo, J. F. P. (2016). Compendio de Literatura griega. Madrid: San Dámaso.

Bowra, C. M. (1958). Alejandría en adelante. En Literatura Griega (pp. 776-796). México DF: Fondo de Cultura Económica México.

Brioso, M. (1987). Los epigramas literarios de Calímaco. Madrid: Gredos.

Brioso Sánchez, M. (1988). Literatura Helenística. En J. A. López Férez (Ed.), Historia de la literatura griega (pp. 781-816). Madrid: Cátedra.

Calímaco. (1974). Epigramas (Trad. L. A. de Cuenca.). Madrid: Suplementos de Estudios Clásicos.

Castellet, J. M. (1970). Nueve novísimos poetas españoles. Barcelona: Península.

Catulo. (1993). Catulo. Poemas; Tibulo. Elegías (A. Soler Ruiz, Trad.). Madrid: Gredos.

de Cuenca, L. A. (1974). Calímaco epigramista. En Calímaco Epigramas. Suplementos de Estudios Clásicos.

de Cuenca, L. A. (Ed.). (1976). Euforión de Calcis: Fragmentos y epigramas. Madrid: Fundación Pastor de estudios clásicos.

de Cuenca, L. A. (1987). El otro sueño. Sevilla: Renacimiento.

de Cuenca, L. A. (1993). El hacha y la rosa. Sevilla: Renacimiento.

de Cuenca, L. A. (1999). Mi poesía. En T. J. Dadson y D. W. Flitter (Eds.), Ludismo e intertextualidad en la lírica española moderna. Birmingham: The University of Birmigham Press.

de Cuenca, L. A. (2006). Mis traducciones poéticas. Ínsula: revista de letras y ciencias humanas, 717, 30-32. 
de Cuenca, L. A. (2013). La alegre brisa de la calle. En Luis Alberto de Cuenca (pp. 15-29). Madrid: Fundación Juan March.

de Cuenca, L. A. (2014). Luis Alberto Cuenca: "La cultura no es de izquierdas ni de derechas» (E. Rodríguez). Turia. Recuperado de : http://www.ieturolenses.org/revista_turia/index.php/actualidad_turia/cat/conversacion es/post/luis-alberto-cuenca-la-cultura-no-es-de-izquierdas-ni-de-derechas/

de Cuenca, L. A. (2018). Bloc de otoño. Madrid: Visor.

Genette, G. (1989). Palimpsestos: La literatura en segundo grado. Madrid: Taurus.

Giangrande, G. (1984). Carácter de la poesía helenística. Anuario de estudios filológicos, 7 , 155-171.

Gil de Biedma, J. (1998). Las personas del verbo. Barcelona: Seix Barral.

Guattari, F. y Rolnik, S. (2006). Cartografías del deseo. Buenos Aires: Traficantes de Sueños.

Lanz, J. J. (2018). Traducción y variación: Estrategias de intertextualidad en Luis Alberto de Cuenca. En A. Sáez (Ed.), Las mañanas triunfantes: Asedios a la poesía de Luis Alberto de Cuenca (pp. 67-103). Sevilla: Renacimiento.

Latham, A. (2017). Diccionario enciclopédico de la música. México DF: Fondo de Cultura Económica.

Lesky, A. (2003). Los nuevos centros. En Autor, Historia de la literatura griega (pp. 725749). Madrid: Gredos.

Letrán, J. (2005). La poesía postmoderna de Luis Alberto de Cuenca. Sevilla: Renacimiento.

Perrotta, G. (1925). Alejandrinismo. Recuperado de: https://www.criticadelibros.com/generos-literarios/alejandrinismo/

Ponce Hernández, C. (2013). Apuntes sobre el léxico del poema VII de Catulo. Anuario de Letras Moderna, 18, 215-224.

Sierra Cózar, A. (1991). Luis Alberto de Cuenca, poeta de dos décadas. Nueva Revista, 15, 84-85.

Suárez Martínez, L. M. (2010). La tradición clásica en la poesía de Luis Alberto de Cuenca. Pontevedra: Academia del Hispanismo.

\section{Notas}

\footnotetext{
${ }^{1}$ Esta forma de construcción de una dimensión urbana novedosa es descrita por Albin Lesky (2003) de la siguiente forma: "Uno de los rasgos más llamativos del helenismo es una inclinación a lo supradimensional, en lo cual parece perpetuarse algo del espíritu de Alejandro. Surgieron las ciudades recién fundadas con gigantescas dimensiones y su construcción hipodámica, que permitía que las largas arterias se cruzaran rectangularmente; a todas sobrepujó Alejandría con sus instalaciones portuarias, con el faro en la isla de Faros, obra de Sóstrato de Cnido, posteriormente considerada como una de las maravillas del mundo, y con el sector real, que, con los edificios para las dependencias palaciegas, los cuarteles, la cancillería, el Museo y un teatro, constituía una ciudad dentro de la gran ciudad" (pp. 727-228).

${ }^{2}$ Félix Guattari y Gilles Deleuze han postulado la importancia de esta noción y han desentrañado su funcionamiento en un libro célebre como Mil Mesetas. Esta comprensión dinámica del espacio probablemente pueda colaborar a comprender cómo se configura la experiencia vital durante este periodo. Guattari explica, en este sentido, que la noción de territorio debe desbordar el uso que hacen de él la etología y la etnología: "Los seres existentes se organizan según territorios que ellos delimitan y articulan con otros existentes y con flujos cósmicos. El territorio puede ser relativo tanto a un espacio vivido como a un sistema percibido dentro del cual un sujeto se siente 'una cosa'. El territorio es sinónimo de apropiación, de subjetivación fichada sobre sí misma. Es un conjunto de representaciones las cuales van a desembocar, pragmáticamente, en una serie de comportamientos, inversiones, en tiempos y espacios sociales, culturales, estéticos, cognitivos" (Guattari y Rolnik, 2006, p. 372).

${ }^{3}$ Ello, sin embargo, no niega una dimensión vital del poema que será comprendida en su construcción estrictamente cultural, como modelo retórico. Por otra parte, podríamos llegar a afirmar que, barroquismo
} 
mediante, la primera escritura de Luis Alberto de Cuenca establece con la serie biográfica, pese a negarlo programáticamente, una conexión cercana, más si observamos el abordaje y escenificación de la muerte de Rita Macau en Elsinore. En la poesía de línea clara, por el contrario, a pesar de encontrarnos con un flujo reconocible y reconocido de nombres propios, espacios y tiempos en clave autobiográfica, el distanciamiento de su escritura parece postular el carácter enteramente literario de su inclusión.

${ }^{4}$ Giusseppe Giangrande, al observar la técnica alusiva de los poetas helenísticos, propone un paralelismo que puede explicar la fascinación de los "poetas modernos" con la escuela alejandrina: "Los poetas modernos, como por ejemplo Leopardi o Cavafis, no tienen que crear una nueva lengua poética: la lengua poética existe ya, es el resultado de muchos siglos de desarrollo (en el caso de los poetas italianos la lengua poética fue creada por Dante y los otros poetas medievales, y Petrarca). Los poetas helenísticos debieron hacer frente al mismo problema: no podían crear una lengua poética nueva porque esta lengua poética existía ya, producto de muchos siglos de desarrollo, a partir de Homero" (Giangrande, 1984, p. 160).

${ }^{5}$ En este aspecto, el alejandrinismo de la línea clara no parece alejarse demasiado de su propia poesía novísima. Ello es observado por el propio Luis Alberto de Cuenca cuando evalúa la modernidad que trajeron los novísimos al panorama español: "Eso era lo moderno, más que dedicar cantos al pueblo, hablar de liberación y enarbolar banderas rojas por todas partes. Todo eso nos resultaba arcaico y en ese sentido, como corriente de ruptura, de innovación, la generación novísima fue importante. Se recuperaron valores lingüísticos en un momento en que la lengua estaba, en cierto modo, echada a perder; se dio valor a la cultura, y no sólo a la española, sino a la universal, a la que la generación social, o progre, no prestaba atención. Los novísimos abrimos un poco la ventana para dejar que la brisa entrara en la biblioteca, que estaba un poco llena de polvo" (de Cuenca, 2014).

${ }^{6}$ Este género será cultivado, por lo menos bajo esa titulación, únicamente en los libros El hacha y la rosa (1993) y en Bloc de Otoño (2018). Las variaciones, por lo general, abordan textos antiguos como resulta el caso de las siguientes composiciones: "Sobre un pasaje del canto VI del Mahabhárata" (de Cuenca, 1993, pp. 348-349), "Sobre una oda de Horacio" (de Cuenca, 1993, pp. 350-351), "Variación sobre un tema de Catulo" (de Cuenca, 2018, p. 84), "Variación sobre otro tema de Catulo" (de Cuenca, 2018, p. 85), "Variación sobre un tema de Íbico" (de Cuenca, 2018, p. 86), "Variación sobre un tema de Mimnermo" (de Cuenca, 2018, p. 87), "Variación sobre otro tema de Mimnermo" (de Cuenca, 2018, p. 88); "Variación sobre un tema de Alcmán" (de Cuenca, 2018, p. 89), "Variación sobre un tema de Safo" (de Cuenca, 2018, p. 90), "Variación sobre un tema de Simónides" (de Cuenca, 2018, p. 114), "Variación sobre otro tema de Simónides" (de Cuenca, 2018, p. 115), "Variación sobre un tema de Arquíloco" (de Cuenca, 2018, p. 116) y "Variación sobre otro tema de Arquíloco" (de Cuenca, 2018, p. 117). No obstante, también encontramos variaciones referentes a textos modernos: "Sobre un tema de J. M. M." (LCDP: 210), "Sobre un poema de Bertran de Born" (de Cuenca, 1993, p. 84), "Sobre un poema de Lacenaire" (de Cuenca, 1993, p. 86), "Sobre un poema de Baudelaire" (de Cuenca, 1993, p. 88), "Sobre un poema de Robert Ervin Howard" (de Cuenca, 1993, p. 90), "Variación sobre un pasaje de Fausto" (2018, p. 41) y "Variación sobre otro pasaje de Fausto" (2018, p. 42). Esta vertiente alejandrina, por otra parte, ha sido también cultivada por otro poeta coetáneo a nuestro autor, como Víctor Botas (1946-1994). Tanto en su libro Segunda mano (1982) como en Historia Antigua (1987), este poeta asturiano recupera el género de la variación utilizando, además, un corpus poético evidentemente caro a Luis Alberto de Cuenca: Arquíloco, Safo, Anacreonte, Simónides, Calímaco, Catulo, etcétera.

${ }^{7}$ Alison Latham explica que las variaciones son una forma musical en la que un tema completo se repite pero con algunas modificaciones a cada reexposición. Las variaciones pueden ser continuas, como en los movimientos en ostinato, o con modificaciones discretas, como en las variaciones estróficas. La especialista explica que no hay un número fijo de variaciones sobre un tema. Como género, además, las variaciones estróficas jamás han gozado de gran prestigio, en cierta medida debido a su forma paratáctica (encadenamiento de secciones separables) que da la impresión de una simple secuencia de piezas breves unidas entre sí, sin coherencia formal. Sin embargo, muchos compositores han reunido variaciones individuales para crear patrones retóricos y formas musicales mayores. "En manos de compositores notables", advierte Latham, "el trabajo con variaciones sobre un tema ha creado obras dinámicas y convincentes, pero la mayoría de las variaciones compuestas para el consumo popular suele ser artísticamente trivial". Esta diversidad en los resultados finales del trabajo de variación la llevan a concluir que "la forma (de las) variaciones sobre un tema tiene la peculiaridad de ser adaptable tanto a las expresiones más vacuas como a las más profundas de la música instrumental occidental" (Latham, 2017, p. 1554).

${ }^{8}$ Gérard Genette (1989), en su libro Palimpsestos, menciona, sin definirla en detalle, la noción de variación, entendida como una forma de transposición: "La variación, que afecta a un tema original (Variations Goldberg, de Bach) o tomado de otro (Variations Diabelli, de Beethoven) constituye por sí misma una forma o un género musical completo, en el que se combinan todas las posibilidades de transformación, canónicas o no -y es sabido hasta qué punto las explotó Beethoven” (p. 483). A su vez, el teórico presenta una modalidad más libre de 
transposición, como lo es la paráfrasis que "florea sobre uno o varios temas prestados toda una red de improvisaciones ad libitum" (Genette, 1989, p. 483).

${ }^{9}$ Podríamos agregar que el texto luisalbertiano tiene como antecedente en la serie española un poema de Jaime Gil de Biedma titulado "Pandémica y celeste" (Gil de Biedma, 1998, p. 143). Ese texto, sin embargo, no parece ser retomado por nuestro poeta, a excepción de que ambos tienen un hipotexto en común.

${ }^{10}$ Ello aparece claramente explicado bajo la forma de la miopía en su arte poética "La alegre brisa de la literatura": "Normalmente, los poetas menores no deberían dedicarse a las letras mayores, sino a las diminutas. En este caso, el poeta menor es, además, miope y refractario (de momento) a las operaciones de miopía con rayo láser, y debe limitarse, pues, a encarar en sus versos temas gruesos, elementales, burdos, básicos... Ello quiere decir, trasladado a la esfera de los sentimientos, que el poeta cegato sólo es capaz de discernir, y en consecuencia de apreciar, pasiones evidentes como el amor, la amistad y el odio, y que, en el plano de las sensaciones, se limita a captar las menos sutiles, como placer, dolor, calor y frío. Con semejantes motivaciones líricas nuestro minor poet corre el peligro de situarse al margen de la exquisitez presumible en un alumno de las Musas" (de Cuenca, 2013, pp. 26-27). 